\title{
A representação visual do som em Eruvë através da onomatopeia
}

\author{
The visual representation of sound in Eruvë through onomatopoeia
}

Janaina Freitas Silva de Araújo, Eva Rolim Miranda, Amaro Xavier Braga Junior

onomatopeias, representação gráfica, histórias em quadrinhos, mangá

\begin{abstract}
A representação gráfica do som através das onomatopeias é uma prática característica das histórias em quadrinhos (HQs). Entretanto, para os tradicionais mangás, ou HQs japonesas, a onomatopeia não se trata apenas do desenho do som. Como a escrita oriental possui uma proximidade muito mais próxima com a representação pictórica e esquemática (Miranda, 2015; Frutiger, 2007), as onomatopeias também são utilizadas como um elemento gráfico de composição da página do mangá, ganhando tipografias próprias, traço único e chegando até mesmo a ser mais importante que o próprio personagem na narrativa. Nosso objetivo foi observar, através de estudo de caso, o processo antropofágico proporcionado pela evidência de novas categorias para a onomatopeia na obra Eruvë, um mangá brasileiro. Como resultado, propusemos quatro categorias. Entre estas, abordamos a complexidade da representação gráfica ocidental ao tratar da estética do som de emoções.
\end{abstract}

onomatopoeia, graphic representation, comics, manga

The graphic representation of sound through onomatopoeia is a characteristic practice of comic books (HQs). However, for traditional manga, or Japanese comic books, onomatopoeia is not just about sound design. As oriental writing has a much closer proximity to pictorial and schematic representation (Miranda, 2015; Frutiger, 2007), onomatopoeia are also used as a graphic element of the composition of the manga page, gaining its own typography, unique trait and arriving even to be more important than the character himself in the narrative. Our objective was to observe, through a case study, the anthropophagic process provided by the evidence of new categories for onomatopoeia in the work Eruvë, a Brazilian manga. As a result, we proposed four categories. Among these, we approach the complexity of Western graphic representation when dealing with the aesthetics of the sound of emotions.

\section{Introdução}

Eruvë, ou "Eruvë: o conto da dama de vidro", é uma história em quadrinhos brasileira independente que foi lançada em 2015, idealizada por Mariana Petrovana e sua equipe, da qual a primeira autora é participante e colaborou com o processo de criação da obra. Eruvë também foi classificado como um mangá por Braga Jr. (2019) e Luyten (2000), assim como pela criadora da obra, pela sua influência estética e de alguns aspectos narrativos típicos desta tipologia de história em quadrinho (HQ) japonesa. Um dos elementos que caracteriza o mangá, de modo geral, é o elemento da onomatopeia (Braga Jr., 2019), e foi através dele que iniciamos nossas investigações sobre a aproximação e as divergências entre Eruvë, um mangá brasileiro, em relação a um mangá japonês convencional. Para tanto, ao analisarmos as

Anais do $10^{\circ} \mathrm{CIDI}$ e $10^{\circ} \mathrm{CONGIC}$

Kelli C.A.S. Smythe, Rafael de Castro Andrade (orgs.)

Sociedade Brasileira de Design da Informação - SBDI

Curitiba | Brasil | 2021
Proceedings of the $10^{\text {th }} \mathrm{CIDI}$ and $10^{\text {th }}$ CONGIC

Kelli C.A.S. Smythe, Rafael de Castro Andrade (orgs.)

Sociedade Brasileira de Design da Informação - SBDI Curitiba | Brazil | 2021 
onomatopeias, percebemos como estas são representações de "sons" não necessariamente miméticos, como é discutido pela percepção teórica ocidental acerca das HQs (McCloud, 2007; Eisner, 2010). Na percepção oriental, as onomatopeias, ou kakimoji (termo utilizado para a prática de "escrever a emoção"), podem ser tanto empregadas de uma forma mimética ou por meio de onomatopeias propriamente ditas. Para os mangás japoneses, a onomatopeia pode ser utilizada não só para representar sons que nós ouvimos naturalmente através de um processo físico-biológico da percepção sonora, mas ela principalmente é utilizada nos mangás a fim de apresentar, pela grafia, o "som" de estados, emoções e atmosferas (Inose, 2007).

Há, contudo, um afastamento entre o mangá japonês e o mangá brasileiro por diferentes aspectos da configuração gráfica do artefato, influenciada cultural e socialmente (Braga Jr., 2019). Neste contexto, utilizamos a análise de algumas características gráficas do enfoque da pesquisa, a onomatopeia, a fim de propormos uma nova classificação para a representação do "som" no mangá brasileiro, tomando como partida o estudo de caso do mangá Eruvë. Entre as características observadas nas onomatopeias, destacamos o traço (união proposta entre os elementos ponto e linha); a cor; escala; e o movimento (Dondis, 2015; Lupton e Philips, 2018).

O estudo de caso foi proposto devido ao levantamento bibliográfico acerca de estudos com enfoque na análise gráfica e/ou editorial de mangás independentes brasileiros. Assim como apontam Twyman (1985) e Miranda (2015), os artefatos gráficos são compostos por características gráficas que, ao serem analisadas separadamente e em relação ao seu contexto na aplicação destes, contribuem para o processo de categorização. As onomatopeias, por sua vez, são um elemento característico das histórias em quadrinhos e, a fim de categorizar estas por meio do Design, consideramos a natureza multidisciplinar desta área do conhecimento. Desta forma, analisamos alguns autores que fazem parte da crítica às narrativas gráficas, principalmente no que diz respeito ao mangá (Luyten, 2000; Braga Jr., 2019); como também alguns autores que abordam o processo de comunicação entre o artefato gráfico e o leitor (Frascara, 2004; Frutiger, 2007).

Ao analisarmos as características gráficas presentes nas onomatopeias encontradas em Eruvë, classificamos estas de acordo com a intenção da autora principal da obra (Mariana Petrovana), nossa interpretação desta intenção por meio da escolha gráfica observada em cada onomatopeia, e, por fim, pelas considerações de um grupo específico de leitores que foi selecionado para esta pesquisa, composto por designers e quadrinistas (foram 20 participantes no total que concordaram em analisar as categorias propostas pelo estudo). Entre as categorias propostas, destacamos: "som de natureza", "som de objeto", "som de personagem" e "som de emoção".

\section{Referencial Teórico}

Luyten (2000), ao tentar propor uma categorização para as onomatopeias ocidentais em relação às onomatopeias encontradas em mangás japoneses, criou cinco categorias: (1) sons da natureza; (2) sons de animais; (3) sons humanos; (4) sons mecânicos; e (5) emoções. É 
pertinente destacar que o número de exemplos de onomatopeias ocidentais em relação às japonesas é menor, mas isso não significa que uma possua mais termos que a outra ou que sejam palavras sinônimas, equivalentes. Contudo, esta aproximação comparativa não considerava aspectos gráficos das onomatopeias como propõe este estudo.

Um ponto relevante sobre a pesquisa realizada por Luyten (2000) em relação a comparação das onomatopeias japonesas com as ocidentais é que as categorias destas não estão pontuadas de maneira equivalente ao que os dicionários japoneses apontam (Inose, 2007). Eruvë, enquanto mangá brasileiro, apresenta onomatopeias que poderiam ser classificadas através deste sistema proposto por Luyten (2000), ao abordarmos a análise das onomatopeias considerando a origem da representação do "som" - natureza, animal, ser humano, máquina ou emoção - e seus aspectos fonéticos. Contudo, buscamos um conceito mais aproximado à adaptação da onomatopeia japonesa pelo processo de antropofagia (Braga Jr., 2019). Este considera outras formas de registro da onomatopeia enquanto elemento verbal e pictórico que como onomatopeia propriamente dita ou palavra mimética (Inose, 2007).

Sobre a interpretação das onomatopeias como um elemento que pode variar de significado a depender do contexto social e cultural no qual esta surge e é incorporada à prática da linguagem, seja ela verbal ou pictórica (Twyman, 1985; Miranda, 2015), observa-se como a ressignificação ocorre através de transcrição do sentido. Lyons (1977) já discutia sobre as diferenças entre as interpretações da onomatopeia enquanto elemento verbal e quando esta é apresentada como um elemento pictórico. A onomatopeia ocidental "ring ring", por exemplo, pode ser compreendida enquanto ícone para a ação do telefone tocando. Para Lyons (1977), ela só apresenta sentido icônico para o tocar do telefone enquanto interpretada como elemento verbal, ou na modalidade fonética. Na modalidade gráfica, ou pictórica, Lyons (1977) afirma que as onomatopeias funcionam como símbolos significando o ícone da modalidade fonética. Desta maneira, a modalidade gráfica da onomatopeia também atribui significado a fonte dela, a imagem a qual faz referência. Na linguagem escrita, a onomatopeia ainda pode ganhar uma terceira interpretação como elemento que envolve um processo de comunicação que cria seu significado por meio do diálogo (Lyons, 1977). Podemos sugerir, portanto, que nas HQs, a onomatopeia pode assumir três sentidos, seja ela apresentada enquanto elemento verbal, pictórico e/ou esquemático (Twyman, 1985; Miranda, 2015).

As onomatopeias nos comics costumam ser classificadas em palavras quando estão inseridas dentro de um balão (como risada, tosse, murmúrio, etc.) e como efeito sonoro quando estão fora deste. Sendo assim, é possível aferir que o sentido das onomatopeias também é determinado pela presença do balão. Existem ainda onomatopeias que conseguem criar um sentido misto entre estarem no balão e fora dele (estourando a marcação da margem do balão) e outros casos em que a onomatopeia (de uma risada, por exemplo) que geralmente é incorporada ao balão, é apresentada fora dele, proporcionando outro sentido à onomatopeia (Guynes, 2014). A delimitação do balão, todavia, cria um espaço cognitivo em HQs de modo geral. Em Eruvë, muitas das onomatopeias observadas não possuem limitação pelos balões, algumas até extrapolando as limitações dos quadros. Guynes (2014) aponta a presença da 
onomatopeia fora do balão como efeito sonoro que compreende uma associação entre a palavra e a imagem. Nos mangás japoneses, e em Eruvë, este tipo de onomatopeia (efeito sonoro - SFX - de acordo com a visão dos comics) está presente constantemente, promovendo o que Luyten (2000) trata como estética do som, associando-o ao elemento pictórico das imagens e não necessariamente ao elemento verbal das palavras presentes nos balões.

A criação da onomatopeia depende do repertório artístico do quadrinista, visto que as influências gráficas que este possui podem influenciar na escolha de como representar suas próprias criações. Em Eruvë, assim como ocorre com muitos mangás brasileiros, suas criadoras não possuíam educação artística formal. Frascara (2004) aborda o processo de percepção gráfica e visual como uma "alfabetização". Entretanto, o cenário da produção de HQs no Brasil é diferente do norte-americano (com a indústria de comics) e o próprio mercado japonês de mangás, pois estes já possuem tantas instituições educacionais especializadas no ensino técnico do desenho para HQs (International School of Comics Chicago, The Kubert School, por exemplo), como também há uma forte frente acadêmica no que diz respeito a pesquisas na área de crítica a narrativas gráficas (Canadian Society for the Study of Comics, The Japan Society for Studies in Cartoons and Comics). Enquanto isso, no Brasil, a grande produção de HQs nacionais é feita por quadrinistas independentes, financiados coletivamente, que, em sua maioria, são autodidatas (Araújo, 2018).

As onomatopeias, ao serem aplicadas em HQs, possuem valores sonoros e icônicos (Frutiger, 2007). Este último ocorre quando a onomatopeia está representando além do som, aspectos da representação gráfica, como por exemplo, forma, textura, tom, escala, dimensão, movimento. Desta forma, para se conhecer a onomatopeia, principalmente nos mangás que apresentam um grande número de variáveis destas, não se faz necessário conhecer seu significado a priori. O leitor de HQs pode reconhecer o significado das onomatopeias quando estas estão representadas graficamente em conjunto com o restante dos elementos da página do quadrinho. Este conjunto é que orienta o leitor a interpretar a onomatopeia.

Nos mangás, há representações gráficas do som por meio de uma aproximação diegética que busca representar os sons na narrativa tal como eles seriam de fato dentro da realidade do universo representado. Esta aproximação ocorre pela construção da hierarquia das informações na narrativa, colocando, por exemplo, a onomatopeia em primeiro plano, ou não. A representação de "sons reais" com o uso da onomatopeia se aproxima mais da classificação proposta por Inose (2007) ao considerar palavras miméticas do que de fato criar onomatopeias tal como são compreendidas no mangá. Em Eruvë, por exemplo, podemos observar a presença de onomatopeias tanto como um elemento em primeiro plano, mais importante para o processo de compreensão da narrativa pelo leitor, como em último plano, alimentando a atmosfera criada pela representação do cenário.

As onomatopeias, de todo modo, são interligadas diretamente com a representação gráfica das imagens na narrativa. Este processo fica mais claro quando a onomatopeia é percebida como agregadora de características sonoras ao elemento gráfico. Nos mangás, por sua vez, esta representação gráfica da onomatopeia é utilizada, principalmente, para representar 
sentimentos, estados, emoções e atmosferas. Através da classificação proposta por esta pesquisa para as onomatopeias, investigamos como ocorre a aproximação com ideia de que emoções e sentimentos podem ser representados graficamente por meio de um elemento prioritariamente verbal como é o emprego de fontes tipográficas em quadrinhos (Inose, 2007).

\section{Metodologia}

Ao classificarmos os "sons" em Eruvë, observamos como as características gráficas destes foram aplicadas de acordo com a intencionalidade da autora ao criá-las para a narrativa. Utilizamos as categorias observadas por Luyten (2000) e Inose (2007) para a representação do "som" em mangás japoneses (giseigo, gitaigo - palavras miméticas; e giongo e gijogo onomatopeias propriamente ditas) a fim de compreender melhor como a representação gráfica em um mangá como Eruvë poderia alcançar o público brasileiro, sendo este classificado como tal. É importante destacar que nosso intuito não foi traduzir as onomatopeias japonesas e aplicá-las à Eruvë. Esta obra não é um mangá mimético neste aspecto. Mariana Petrovana e Janaina Araújo observaram e analisaram as onomatopeias que já haviam sido inseridas no mangá em 2015, e as organizaram em grupos maiores, categorizando-as de acordo com a intenção de representação que buscaram transmitir ao público leitor.

Observamos como, apesar dos esforços de pesquisadores na área de crítica a narrativas gráficas em tentar criar categorias para as onomatopeias japonesas em mangás que fossem equivalentes a produções ocidentais, esta categorização não levanta a perspectiva dos quadrinistas produtores de mangás brasileiros (Luyten, 2000; Inose, 2007; Braga Jr., 2019). Além disso, as análises partem principalmente do âmbito da Literatura, Linguística ou Comunicação, raramente do campo do Design, considerando aspectos gráficos e da composição da informação visual na narrativa. Desta forma, para que fosse possível propor uma nova categorização para as onomatopeias em mangás brasileiros, foi necessário realizar um estudo de caso, considerando não só o contexto de criação de Eruvë (produzido de forma independente), mas também considerarmos principalmente as caracterizações gráficas das onomatopeias encontradas. Sendo assim, separamos cada onomatopeia encontrada de acordo com o traço (irregular ou regular); a cor (com alto ou baixo contraste); a escala (pequena, média ou grande); e o movimento (vertical, horizontal ou diagonal) (Lupton e Philips, 2018; Dondis, 2015).

Além das características gráficas abordadas, observamos que a onomatopeia também é considerada como elemento que cumpre papel cultural, social e filosófico por carregar o repertório da representação gráfica formado pelas influências de seu criador. Sendo assim, a onomatopeia pode ser considerada um elemento que faz parte de um sistema orgânico. Desta forma, para validar as categorias propostas pela pesquisa, criamos um grupo de foco com 20 participantes pré-selecionados que foram divididos em dois grupos: quadrinistas e designers. $O$ critério para esta pré-seleção foi que os indivíduos não tivessem participado de nenhuma etapa de produção de Eruvë, sendo os designers graduados ou estudantes de diferentes níveis de 
aprendizado; e os quadrinistas com experiência no âmbito do quadrinho independente no Brasil.

A onomatopeia também pode ser compreendida como um elemento que sofre influência do código previsto pela linguagem a qual lhe deu origem, considerando-a enquanto elemento verbal, mas principalmente à imagem a qual ela faz referência nas HQs, ou até mesmo ao sentido da própria narrativa, apresentando-se como um elemento condutor da mesma (McCloud, 2007; Eisner, 2010). Por isso, quando se fala sobre onomatopeia na literatura ocidental, é comum que a mesma seja tratada como "efeito sonoro" ou a "representação do som". Entretanto, pouco se destaca sobre como esta representação é realizada e como as características desta podem influenciar na percepção do leitor (Guynes, 2014). A partir deste raciocínio, tabulamos as onomatopeias encontradas em Eruvë considerando as características gráficas destas, a intenção da criadora ao aplicá-las, a validação pelo leitor através do grupo de foco, e, paralelo a este processo, uma análise descritiva e comparativa entre as influências gráficas de Mariana Petrovana. Esta análise foi realizada com o uso de mapa de influências (Figura 1), preenchido pela própria autora de Eruvë, pontuando suas referências artísticas, desde outros quadrinhos (mangás japoneses e brasileiros); filmes (animação, filmes de fantasia e ficção); e as produções de artistas menos contemporâneos e distantes da mídia popular (como a produção de Alphonse Mucha através do Art Nouveau).

Figura 1: Mapa de influências de Mariana Petrovana, autora de "Eruvë: O conto da dama de vidro", 2015. Fonte: Acervo da(o) autor(a) do artigo, integrante da equipe que produziu também Eruvë. A imagem foi concedida por Mariana Petrovana em 2020.

\section{MARIANA PETROVANA}

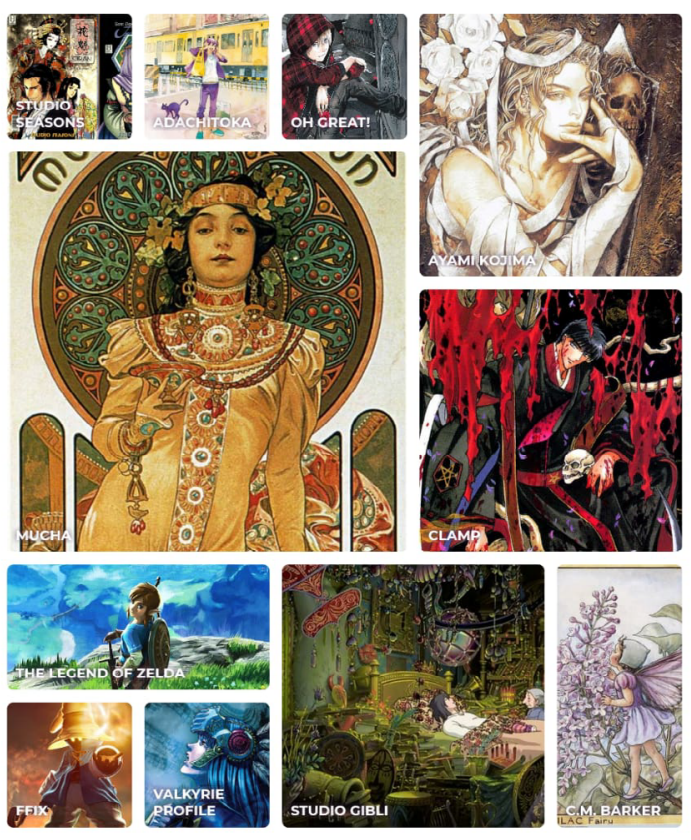

LABS.ICONIC.NETWORK/MAPA 


\section{Resultados e Discussão}

Através da tabulação de 182 onomatopeias encontradas em Eruvë, chegamos a quatro categorias distintas: "som de natureza"; "som de objeto"; "som de personagem" e "som de emoção" (Figura 2). A categoria de "som de natureza" foi separada assim pela origem da representação gráfica da onomatopeia ser um fenômeno natural; o "som de objeto" tem como origem uma figura inanimada; o "som de personagem" é oriundo das personagens em meio à narrativa, relacionado à indicações sobre estas ou acerca de "ruídos" produzidos por elas; e o "som de emoção" foi uma categoria criada para indicar o estado, atmosfera, da personagem ou da cena apresentada na narrativa.

Por meio desta categorização, convidamos os integrantes do nosso grupo de foco, composto por quadrinistas e designers, a concordarem, ou não, com esta proposta. Como é possível observar, na Figura 2, não foram todas as categorias que foram aceitas em sua totalidade. A categoria de "som da natureza" foi interpretada como "som da natureza" pela maioria, assim como "som de objeto". Entretanto, a categoria de "som de personagem" e "som de emoção" foram aquelas que criaram maiores discussões pela interpretação do grupo de foco, principalmente a categoria "som de emoção", visto que $40 \%$ dos participantes afirmou não considerar esta categoria como "onomatopeia". Ainda que esta porcentagem não corresponda a maioria dos participantes, esta categoria foi a única cuja opção de não ser uma onomatopeia foi selecionada. É possível perceber, portanto, como a associação gráfica do sentido da representação desta categoria é mais complexo que as outras. Sobre isso, consideramos esta como fonte de nossa principal discussão, a julgar que para os mangás japoneses, representar sentimentos e emoções é um processo previsto pela produção dos quadrinistas; por outro lado, no mangá brasileiro, esta representação gráfica se confunde de uma forma mais descritiva que abstrata - a exemplo da onomatopeia "Medo!" apresentada na Figura 2. 
Figura 2: Categorização das onomatopeias em Eruvë e o resultado do processo de validação pelos integrantes do grupo de foco, composto por designers e quadrinistas. Fonte: Criação do(a) autor(a), 2021.

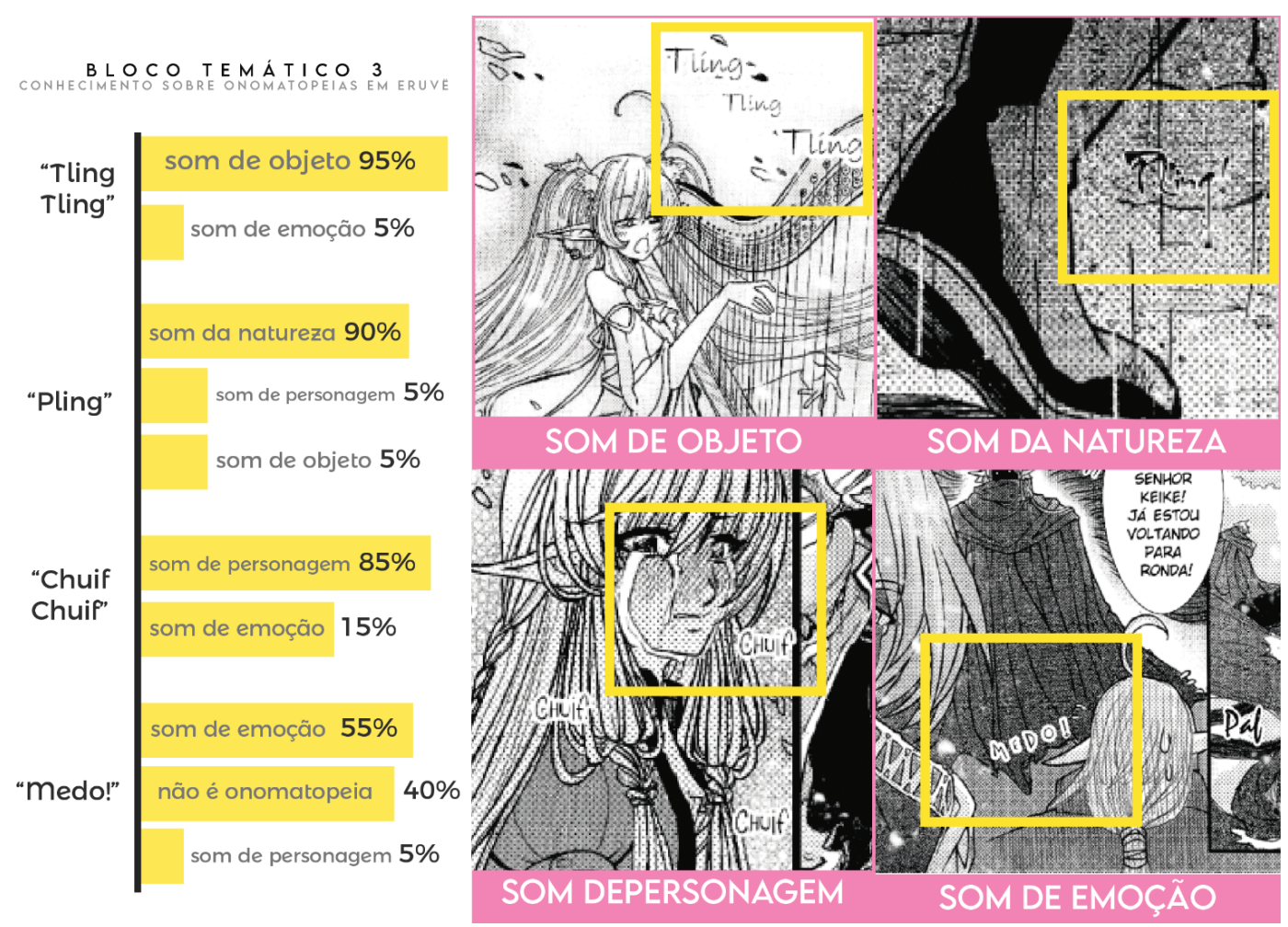

A categoria "som da natureza" foi relacionada à representação de ruídos presentes na natureza, como o soprar do vento e o mover das folhas nas árvores. Foram encontradas nove onomatopeias, no total. $O$ traço destas onomatopeias foi caracterizado como irregular (7/9) e utilizado desta forma pelo intuito de representar uma mancha gráfica de aspecto mais "orgânico". A cor aplicada à onomatopeia apresentava baixo contraste na maioria (8/9), acentuando a representação da onomatopeia como um elemento em segundo plano em relação ao cenário. A escala pequena foi encontrada na maior parte destas onomatopeias (7/9) e enfatiza a ideia deste elemento ser aplicado em segundo plano de modo a compor o cenário. A variação de movimento encontrada nestas onomatopeias foi equilibrada entre vertical (3/9) e diagonal (5/9). Esta última característica gráfica confere maior dinamismo à onomatopeia (Figura 3).

As onomatopeias categorizadas como "som de objeto" foram aplicadas a fim de representar o som que é produzido por objetos, fontes inanimadas, seja por seu "som" próprio (o passar de uma página de livro) ou o "som" que a superfície do objeto oferece em contato com o personagem (o ruído do mapa ao ser tocado). Foram encontradas treze onomatopeias, no total. $\mathrm{O}$ traço destas onomatopeias foi equilibrado entre irregular (6/13) e regular (7/13), o que indica que esta característica gráfica pode não ser a principal para identificar esta categoria. A cor, por sua vez, foi uma característica observada com a prevalência de baixo contraste (10/13). Assim como o "som da natureza", esta categoria faz uso do elemento da onomatopeia 
em baixo contraste em Eruvë a fim de torná-lo ornamental, compondo o cenário da narrativa e não necessariamente guiando o leitor por meio da informação presente no primeiro plano do mangá. Reforçando esta ideia, observamos que a maioria também foi encontrada em pequena escala (9/13). A maioria delas (7/13) apresentou a característica gráfica de movimento entre diagonal e vertical. A prevalência da maioria das onomatopeias com movimento em sentido diagonal sugere maior dinâmica para a narrativa (Figura 3).

Figura 3: Resultado da caracterização das onomatopeias encontradas em Eruvë de acordo com as características gráficas observadas: traço, cor, escala e movimento. Fonte: Criação da autora, 2021.
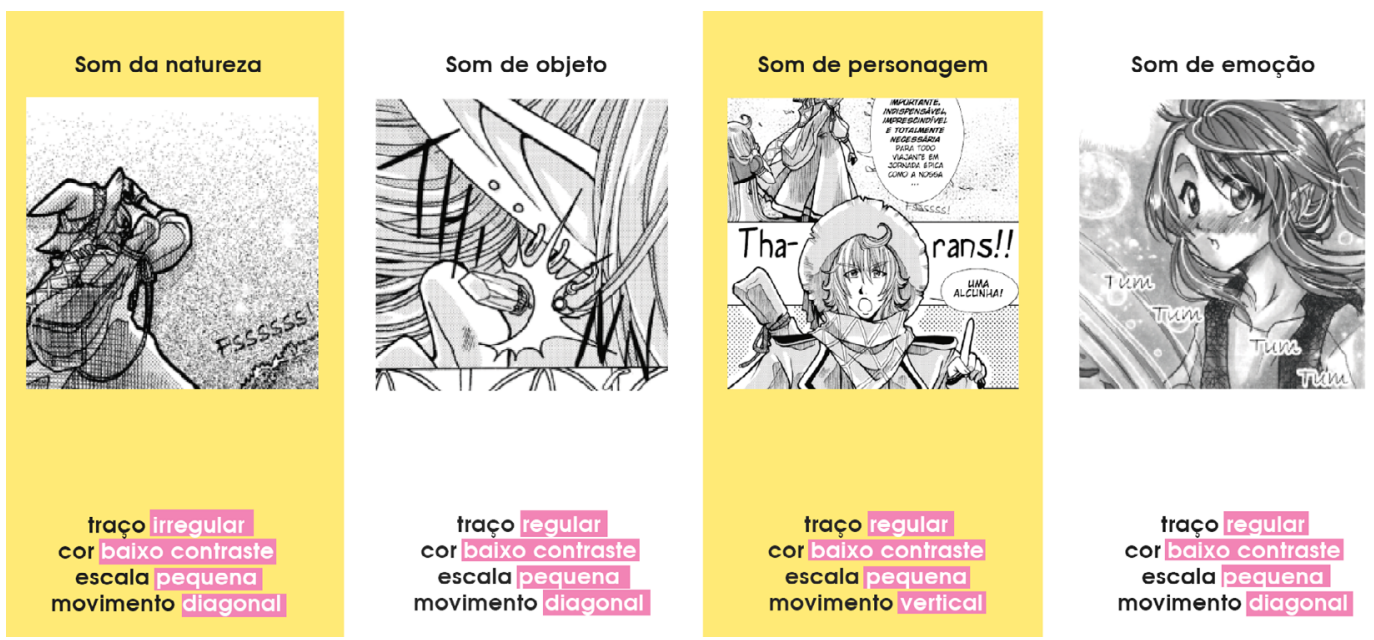

As onomatopeias que foram utilizadas para representar a categoria de "som de personagem" apresentaram maior variação de características gráficas entre as fontes tipográficas (Figura 3). Observamos como as fontes Chiller Regular, VNI HL Thuphap Regular e Angryblue Regular apresentam o corpo das letras construídas de modo a representar alguma textura em específico, como: a escrita em tinta; a escrita em tinta escorrendo; e a escrita em linhas em cortes, respectivamente. As fontes tipográficas mais utilizadas foram: Manga Speak (20); Augie Regular (17); e Wild World (10). Similares entre si, estas são fontes utilizadas em balões de fala encontrados em Eruvë. A presença da mesma fonte tipográfica para a fala e para as onomatopeias de "som de personagem" pode sugerir a proximidade desta categoria com a origem do "som" sendo o personagem que realiza as ações na narrativa.

O traço e a cor, na categoria "som de personagem", são características gráficas encontradas de modo mais equilibrado em relação às outras. Foram encontradas oitenta $e$ duas onomatopeias nesta categoria. A maioria das onomatopeias observadas apresentou traço regular (48/82), baixo contraste (46/82), pequena escala (64/82) e movimento vertical (35/82). Mais uma vez, observamos a priorização do movimento vertical e diagonal (31/82) em relação ao horizontal. É possível que isto ocorra pela necessidade de dinamismo do "som" em relação à narrativa, visto que, assim como ocorre com os quadros, o mangá também é caracterizado por uma perspectiva beligerante (Braga Jr., 2019). Como o "som" é oriundo de um 
personagem, dependendo da escala e do movimento deste, a personalidade do personagem é enfatizada, ou não.

Figura 4: Tabulação das fontes tipográficas encontradas nas onomatopeias de Eruvë e as respectivas categorias do "som" sugeridas por esta pesquisa. Fonte: Criação do(a) autor(a), 2021.

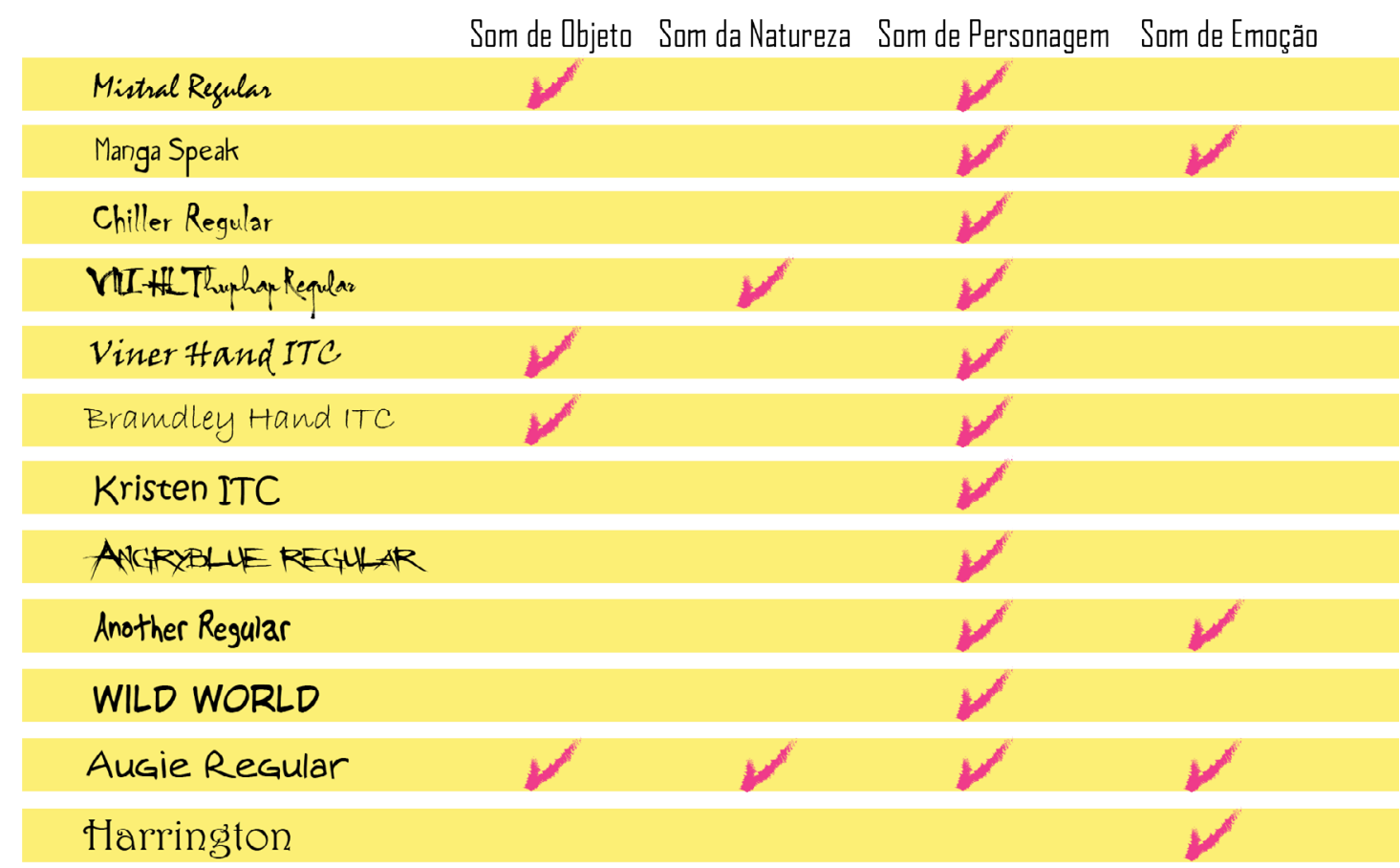

As onomatopeias que foram aplicadas a fim de representar o "som de emoção" utilizam as seguintes fontes tipográficas: Augie Regular; Manga Speak; Another Regular; e Harrington (Figura 3). Esta última, Harrington, foi usada exclusivamente para esta categoria. E, apesar das classificações de "som de personagem" e "som de emoção" estarem separadas, ambas possuem a mesma característica principal: o "som" representado possui origem no personagem que realiza a ação na narrativa. Entretanto, "som da emoção" foi uma categoria construída em referência às onomatopeias categorizadas em mangás japoneses como gijogo, responsáveis pela representação do estado e sentimentos de seres animados.

Ao observarmos as características gráficas do "som de emoção", observamos que esta categoria é composta por um total de cinco fontes tipográficas, entre estas, a maioria foi aplicada em baixo contraste (4/5) e traço regular (4/5). Há similaridade entre a fonte do "som da emoção" e do balão de fala de cada personagem, o que sugere a ideia de que a onomatopeia pertence a estes. A presença do baixo contraste é o que indica o uso da onomatopeia em segundo plano, sendo uma fonte de informação para a narrativa de forma secundária, mas ainda assim importante e complementar. A pequena escala (5/5) enfatiza a presença delas na composição, sem destacá-las como elemento principal da narrativa no momento que o leitor acessa o quadro. O movimento da maioria destas onomatopeias é diagonal (3/5), contudo, esta é uma característica observada também nas categorias apresentadas anteriormente ("som da 
natureza", "som de objeto" e "som de personagem"). As onomatopeias aplicadas em Eruvë possuem uma tendência ao movimento vertical e diagonal pela necessidade de dinamicidade nos elementos gráficos presentes no mangá. Este tipo de liberdade não é encontrado, no entanto, nos balões, cuja informação é prioritariamente textual e configurada de maneira a assegurar a legibilidade da fonte tipográfica para o leitor. As onomatopeias, por outro lado, nem sempre possuem esta mesma preocupação com a legibilidade, sendo apresentadas em baixo contraste em relação ao fundo, pequena escala e em traços irregulares.

\section{Considerações Finais}

As onomatopeias categorizadas como "som de emoção" apresentaram a mesma problemática que as de "som de personagem", encontradas através de palavras presentes no vocabulário da língua portuguesa no Brasil. Para os leitores, é provável que a ideia de que este elemento pode ser categorizado como onomatopeia seja despercebida. Isto ocorre pela interpretação dele apenas como verbal, sem considerarmos suas qualidades gráficas e visuais.

Nosso objetivo, todavia, não foi desvincular a qualidade verbal do elemento da onomatopeia, mas sim enfatizar as outras, de representação gráfica, presentes neste tipo de elemento. Estas também fazem uso de tipografias específicas a depender da emoção que a personagem está sentindo, este tipo de recurso visual também se torna mais claro quando observamos o caso de "Medo!" (Figura 2), categorizada como uma onomatopeia, mas aplicada em tamanho pequeno e com cor em baixo contraste, demonstrando que o sentimento da personagem não é tão intenso quanto à leitura da palavra "medo" sugere. O mesmo ocorre com a onomatopeia "Alívio!!", ambas empregadas com o uso da fonte tipográfica Manga Speak.

A categoria "som de emoção" é mais complexa de representar graficamente, visto que o leitor brasileiro pode não estar habituado a encontrar a onomatopeia por meio de verbos e adjetivos. Contudo, se conseguirmos atravessar este processo de abstração e, ao invés de a encararmos imediatamente como um aglomerado de fonemas ou a escrita de uma palavra, analisarmos este elemento pelas suas características gráficas e visuais, podemos perceber como é capaz de explorar sensações e sentimentos. É possível encontrar, nos mangás japoneses, a referência onomatopaica para quando uma situação é assustadora ou quando o personagem está assustado. Contudo, o registro destes sentimentos não é comum nos mangás independentes como ocorre em Eruvë. Postema (2018) reforça esta ideia ao conceituar a ideia de camadas da linguagem, nas quais o leitor pode ter acesso à informação de acordo com seu repertório. Logo, o processo de inserção de onomatopeias que representam sensações, emoções, pode vir a se tornar uma prática mais frequente nos quadrinhos independentes, principalmente aqueles que estão no nicho do mangá. Entretanto, a interpretação destes depende de adequações de suas características gráficas enquanto elemento que compõe a imagem a fim de guiar a visão do leitor para tal. 


\section{Agradecimento}

Agradecemos à Coordenação de Aperfeiçoamento de Pessoal de Nível Superior (CAPES) pelo incentivo a esta pesquisa.

\section{Referências}

BRAGA JR., A. Histórias em Quadrinhos Japonesas: História, representação gráfica e Impactos Sociais. Núcleo de Educação a Distância da Faculdades EST. São Leopoldo, RS. 2019.

LUYTEN, S. B. Mangá: o poder dos quadrinhos japoneses. 2. ed. São Paulo: Hedra, 2000. McCLOUD, S. Desenhando Quadrinhos. Editora: MBOOKS; Edição: 1ª 2007.

EISNER, W. Quadrinhos e arte sequencial. Editora: WMF Martins Fontes; Edição: 4ª 2010.

DONDIS, A. Sintaxe da Linguagem Visual. Editora Martins Fontes. 2015.

GUYNES, S. A. Four-Color Sound: A Peircean Semiotics of Comic Book Onomatopoeia. Public Journal of Semiotics. 2014

POSTEMA, B. Estrutura narrativa dos quadrinhos: construindo sentido a partir de fragmentos. São Paulo: Peirópolis, 2018.

LUPTON, E.; PHILIPS, J. C. Novos Fundamentos Do Design. Editora Cosac \& Naify. 2018.

TWYMAN, M. Using Pictorial Language: A Discussion of the Dimensions of the Problem. In: DUFTY, T.M; WALKER, R. Designing Usable Texts. Academic Press. 1985.

FRASCARA, J. Communication Design - principles, methods and practice. New York: Allworth Press. 2004.

FRUTIGER, A. Sinais \& Símbolos. Desenho, projeto e significado. Editora Martins Fontes. São Paulo. 2007.

LYONS, J. Semantics. Volume 1. Cambridge: Cambridge University Press. 1977.

ARAÚJO, J. O processo editorial miscigenado: Silent Mangá no Brasil. Monografia - curso de Design. Universidade Federal de Alagoas. Maceió, AL. 2018.

INOSE, H. Translating Japanese onomatopoeia and mimetic words. Dalarna University. 2007.

Miranda. 2015. Focus group reading of a sequential narrative involving the representation of time. In: C. G. Spinillo; L. M. Fadel; V. T. Souto; T. B. P. Silva \& R. J. Camara (Eds). Anais [Oral] do $7^{\circ}$ Congresso Internacional de Design da Informação/Proceedings [Oral] of the 7th Information Design International Conference | CIDI 2015 [Blucher Design Proceedings, num.2, vol.2]. São Paulo: Blucher, 2015. ISSN 2318-6968, ISBN: 978-85-8039-122-0. DOI 10.5151/designpro-CIDI2015-cidi_96

\section{Sobre os autores}

Araújo, J. F.S., Me., UFPE, Brasil < jana.f.araujxo@gmai.com> Miranda, E. R., Dra., UFPE, Brasil <eva.miranda@fau.ufal.br> Braga Jr., A. X., Dr., UFAL, Brasil <amaro@ics.ufal.br> 